\title{
TRADAUTORIAS DE CIEN AÑOS DE SOLEDAD TRADAUTORÍAS DE CIEN AÑOS DE SOLEDAD
}

\author{
Solange Mittmann ${ }^{1}$
}

Resumo: A partir da análise de duas traduções de Cien años de soledad, de Gabriel García Márquez - por Eliane Zagury e por Eric Nepomuceno -, discuto o processo de autoria da tradução, que chamo aqui de tradautoria. Sob a perspectiva da Análise do Discurso fundamentada em Michel Pêcheux, considero aspectos como a interpelação, a determinação dos sentidos por formações discursivas e a metáfora resultante da tensão entre formações discursivas. Como recorte de análise, parto das notas de tradutor (N.T.) de Zagury e da sua ausência na tradução de Nepomuceno. Os diferentes gestos dos tradutores conduzem à reflexão sobre a autoria - como trabalho sobre a enunciação e um modo de enfrentar-se com o que é da ordem da constituição do sujeito e do sentido, pela interpelação e pela intervenção do interdiscurso. Palavras-chave: tradução, Cem anos de solidão, nota do tradutor, formação discursiva, metáfora.

Resumen: A partir del análisis de dos traducciones de Cien años de soledad de Gabriel García Márquez - por Eliane Zagury y por Eric Nepomuceno - discuto el proceso de autoría de la traducción, que llamo tradautoria. Bajo la perspectiva del Análisis del Discurso basada en Michel Pêcheux, planteo aspectos como la interpelación, la determinación de los sentidos por las formaciones discursivas y la metáfora resultante de la tensión entre formaciones discursivas. Los recortes para el análisis son las notas del traductor (N.T.) de Zagury y la ausencia de notas en la traducción de Nepomuceno. Los distintos gestos de los dos traductores conducen a reflexionar sobre la autoría - como trabajo sobre la enunciación y como una manera de sujetarse a lo que está en el orden de la constitución del sujeto y del sentido, a través de la interpelación y de la intervención del interdiscurso. Palabras clave: traducción, Cien años de soledad, nota del traductor, formación discursiva; metáfora.

1 Professora da Universidade Federal do Rio Grande do Sul e membro do GEPAD-RS. Projeto de Pesquisa "Autoria e interpretação de objetos discursivos" (PIBIC-CNPq/UFRGS).

Organon, Porto Alegre, n 53, julho-dezembro, 2012, p. 65-78 
Em março de 2007, durante as comemorações dos 40 anos de Cien años de soledad, Gabriel García Márquez relatou que, num dia de 1967, já com quatro livros publicados, sentou diante da máquina de escrever e começou: "Muchos años después, frente al pelotón de fusilamiento, el coronel Aureliano Buendía había de recordar aquella tarde remota en que su padre lo llevó a conocer el hielo". Disse o autor que não tinha a menor ideia do significado, nem da origem dessa frase, nem de para onde ela iria conduzi-lo. E descreveu: por 18 meses os dedos batendo ritmadamente as 28 letras do alfabeto, para um leitor inexistente período em que ficou sem receber um centavo, enquanto sua mulher renegociava as dívidas.

Ao deparar-se com a cifra de um milhão de exemplares em língua castelhana vendidos, sabiamente interpretou o fato como uma demonstração de que, ao contrário do leitor inexistente de sua página em branco, há uma multidão de leitores famintos por textos em língua castelhana.

Pois hoje em dia podemos pensar também nas multidões de leitores de outras línguas (entre elas a língua portuguesa do Brasil) famintos especialmente por Cien años de soledad, além de, é claro, outros textos de fonte cultural castelhana. $\mathrm{O}$ que nos leva a apontar a relevância do papel político dos tradutores em possibilitar essa aproximação a tantos leitores famintos.

Leitores que, aliás, quando têm em mãos o texto da tradução (as formulações do tradutor, portanto), leem como se estivessem em contato direto com o autor do texto dito original. Para manter-se no conforto dessa ilusão, no esquecimento de que está diante das formulações do tradutor (imbricadas com as do autor), desejam o apagamento de qualquer vestígio do trabalho de tradução.

Esse desejo de invisibilidade ainda hoje se sutenta sobre e é sustentado por um imaginário da tradução como "transporte do significado do original de um idioma para outro". A consequência política do esquecimento de que o texto traduzido é resultado de um trabalho é a desvalorização desse trabalho, o que leva a uma consequência econômica: a resistência ao pagamento justo dos direitos autorais ao tradutor.

Ainda que sob resistência de grande parte das editoras, já encontramos, em edições contemporâneas, o nome do tradutor na folha 
de rosto, mas segue sendo raro encontrá-lo na capa de um livro. Além da ficha catalográfica, da folha de rosto, da capa e da apresentação, um outro lugar de visibilidade do tradutor sob o imaginário da separação de vozes (tradutor/autor) é a nota de rodapé de tradução (ou Nota do Tradutor, ou N.T.).

Apesar de muitas vezes se apresentarem como única saída para os tradutores, diante, principalmente, do que é tomado como intraduzível, em geral as N.T. em textos literários são muito mal vistas tanto por editores como por leitores-consumidores. Como disse certa vez Luis Fernando Verissimo sobre as notas de rodapé, é como sair da cama quentinha para ver que barulho é aquele lá no porão. Isso porque o desvio do olhar do corpo do texto para o rodapé é um movimento desacomodador, que interrompe a fluência, desfaz a ilusão de estar lendo as palavras do autor, expõe a figura do tradutor como um invasor na relação íntima entre leitor e autor e, ainda, leva à imagem de que alguém já desvelou o "original".

Como diz Lyra (1998, p.81) num artigo sobre nota de tradutor: "O que temos aqui é a questão da presença física do tradutor. Sua própria declaração de que chegou primeiro, desvendou um mistério, tornou-se guia e informante do leitor." E desconforta o leitor da tradução lembrar que um outro leitor tenha interpretado antes dele, pois o percebe como lhe impondo autoritariamente uma interpretação particular.

Esse incômodo se sustenta sobre uma concepção tradicional sobre o tradutor como um intruso que deveria, na verdade, funcionar como uma ponte invisível, desaparecendo, sem deixar vestígios logo de concluir sua tarefa.

Já nas concepções contemporâneas - no âmbito dos estudos discursivos, literários ou tradutológicos -, o tradutor pode ser considerado da mesma forma que qualquer leitor proficiente que se depare com o texto dito original, ou seja, como produtor de uma possibilidade de interpretação entre tantas outras, com a diferença de que ele efetua a produção de um novo texto para um novo leitor imaginário inserido em uma outra cultura.

A concepção tradicional se sustenta sobre um pré-construído informacional: um esquema de emissão-recepção, numa via de mão única. Entre as concepções contemporâneas, a que destaco aqui é a que não só rejeita veementemente a mão única, como vai além Organon, Porto Alegre, ํำ 53, julho-dezembro, 2012, p. 65-78 
do imaginário da mão dupla, pois parte do pré-construído de que a produção de efeitos de sentidos só ocorre pela entrada numa rede, pela intervenção da memória discursiva e, ainda, dá-se ao sujeito de modo particular, a partir do lugar social que ocupa e da posição que assume em sua inscrição em uma formação discursiva.

Assim, um aspecto fundamental, que marca diferença na reflexão sobre a tradução, é a forma como se concebe a constituição do discurso: como o discurso se faz de fragmentos de outros que se aproximam ${ }^{2}$, não há fronteira entre dentro e fora, e a unidade se constrói como um efeito pela autoria. Ainda é preciso considerar que tal proximação ocorre a partir da determinação dos sentidos por uma formação discursiva, ou seja, pela interpretação em certa direção, e não em outra possível.

Ao abordar a alteridade e a relação do sujeito com uma segunda língua, Serrani-Infante (1998, p.245) alerta:

De início, é indispensável ter presente que a alteridade discursiva, no quadro das categorias da Análise do Discurso, se situa no nível do interdiscurso. Trata-se aqui de abordar a problemática contraditória da relação língua(gem)-identidade. A concepção de subjetividade que se considera nesta dimensão não é a de falante que encontraria na linguagem um instrumento para exprimir suas "intenções de comunicação", mas, sim, o espaço do sujeito afetado pelo préconstruído e pelo discurso transverso, sujeito do inconsciente, efeito de linguagem, falente, ser em línguas, pego na ordem simbólica que o produz enquanto sujeito.

Ao se pensar o autor e também o tradutor, é preciso, portanto, questionar o imaginário do sujeito como "ator de consciência intencional" e da língua como "instrumento de comunicação do pensamento do sujeito". Não se trata apenas de pensar a presença inevitável do sujeito tradutor no texto da tradução, ou a relação intersubjetiva presente. Pois, nesta perspectiva, passa-se da subjetividade ao assujeitamento, como ensina Pêcheux (2011[1984], p.156): "Isso

2 Conforme descrevo em Mittmann (2010).

3 O próprio García Márquez (1994, p.99) conta de personagens que tomaram características e destinos que "no fueron los que yo quise". A paixão de Aureliano José por sua tia Amaranta "me tomó de sorpresa", José Arcádio Segundo "nunca fue el líder sindical bananero que yo había querido" e José Arcádio, aprendiz de Papa, tornou-se "una especie de Adonis decadente, um poco ajeno a todo el resto del libro". 
supõe que o sujeito deixe de ser considerado como o eu-consciência mestre do sentido e seja reconhecido como assujeitado do discurso: da noção de subjetividade ou intersubjetividade passamos assim à de assujeitamento."

Considerando-se a relação entre o assujeitamento e a tomada de posição, temos a construção do efeito de autoria, como efeito de origem, efeito de responsabilidade, a partir do modo particular de o sujeito se relacionar com a formação discursiva a cada gesto. $\mathrm{O}$ tradutor é determinado por e determinado $a$, tanto quando se encontra no lugar de leitor do texto 1 (o texto de base) como no de autor do texto 2 (o texto da tradução). ${ }^{4}$

Então, a respeito da constituição do sujeito como sujeito tradutor, é preciso considerar, não como um problema contingencial, mas como fator constitutivo, a interpelação do indivíduo em sujeito pela ideologia (através da forma particular de sua inscrição em uma formação discursiva), a injunção à interpretação e o direcionamento dos sentidos. A partir dessas condições é que se dá a construção da autoria da tradução, ou do que passo a chamar de tradautoria - uma forma específica de autoria: a que se constrói no processo tradutório ${ }^{5}$. Importa, então, considerar que apesar de o leitor do texto de tradução só se deparar com as palavras do tradutor, o tradutor pode disfarçar para mais ou para menos a sua presença no processo através do funcionamento da tradautoria.

Pretendo mostrar isso através de duas traduções de Cien años de soledad para o português brasileiro. A primeira é de Eliane Zagury, e a segunda, produzida alguns anos depois, é de Eric Nepomuceno.

$\mathrm{O}$ primeiro trecho que selecionei apresenta o retorno de José Arcadio à casa dos Buendía:

Llegaba un hombre descomunal. Sus espaldas cuadradas apenas si cabían por las puertas. Tenía una medallita de la Virgen de los Remedios colgada en el cuello de bisonte, los brazos y el pecho completamente bordados de tatuajes crípticos, y en la muñeca derecha la aprestada esclava de cobre de los niños-en-cruz.

4 Evito os termos "texto de partida" e "de chegada" por não compartilhar da construção imaginária da via de mão única.

5 Para uma descrição mais ampla desse processo, a partir de uma perspectiva discursiva, ver Mittmann (2003 e 2008).

Organon, Porto Alegre, n 53, julho-dezembro, 2012, p. 65-78 
Diante da formulação “niños-en-cruz", Eliane Zagury inclui uma N.T.:

Chegava um homem descomunal. Os seus ombros quadrados mal cabiam nas portas. Trazia uma medalhinha da Virgem dos Remédios pendurada no pescoço de búfalo, os braços e o peito completamente bordados de tatuagens enigmáticas, e na munheca direita o apertado bracelete de cobre dos niños-en-cruz.*

* Explicação do autor à tradutora: "Segundo uma lenda popular, alguns homens fazem abrir o pulso e ali meter uma pequena cruz especial fechando-o depois com uma pulseira de ferro ou cobre. Isto, segundo a lenda, lhes dá uma força extraordinária."

Debatendo-se com o não-sentido, a tradutora recorre a García Márquez em busca de uma explicação e expõe ao leitor imaginário o embate com que se deparou durante o processo tradutório. Apresenta, então, o autor como aquele que detém o sentido, e a si mesma como aquela que busca por ele. A N.T. nos mostra que a tradução não é transmissão de informação de uma língua para outra, nem interação autor-tradutor-leitor, mas embate com o não-sentido, disputa pela autoria no jogo enunciativo que disfarça/revela o equívoco constitutivo do processo de interpretação/tradução.

Já Nepomuceno, que não utiliza nenhuma N.T. ao longo da obra, traz a explicação para dentro do corpo do texto:

Chegava um homem descomunal. Suas costas quadradas mal cabiam pelas portas. Tinha uma medalhinha da Virgem dos Remédios pendurada no pescoço de bisonte, os braços e o peito completamente bordados de tatuagens misteriosas, e no pulso direito a apertada pulseira de cobre dos niños-en-cruz. Era a lenda incorporada nele: a de que os homens de força insuperável e corpo invulnerável abriam um talho no pulso, enterravam ali uma pequena cruz de metal, e fechavam a cicatriz com a pulseira.

Na leitura do texto de Zagury, o leitor se depara com a bifurcação: a ilusão de que somente a voz do autor se encontra no corpo do texto, enquanto é reservado à N.T. o espaço para a explicitação da voz do tradutor, numa espécie de embate por espaços. Já no texto de Nepomuceno, há um disfarce maior, no momento em que a explicação 
do tradutor é incorporada à própria narrativa, como voz do narrador, sob um efeito de já-sabido: "Era a lenda incorporada nele". Pode-se dizer que, enquanto a tradução de Zagury traz o efeito de discurso transverso, a de Nepomuceno traz o de pré-construído - duas formas de manifestação do interdiscurso.

Tanto o recurso à nota quanto o recurso à explicação pela voz do narrador são duas formas de construir-se como imagem de tradutor para o leitor imaginário. De qualquer forma, é o trabalho de autoria (a tradautoria) que levará a um efeito ou ao outro: ao menor ou ao maior disfarce.

Ainda sobre a autoria, cabe aqui citar a definição de Leda Tfouni (2008, p.141): "o sujeito ocupa a posição de autor quando retroage sobre o processo de produção de sentidos, procurando 'amarrar' a dispersão que está sempre virtualmente se instalando, devido à equivocidade da língua".

$\mathrm{Na}$ tradautoria, pelo funcionamento da função-tradutor, pode-se amarrar/disfarçar a dispersão - própria de todo discurso - levando ao efeito de um (sem a N.T.) ou de dois (com a N.T.), como se somente uma ou duas vozes estivessem aí presentes, mantendo-se a ilusão de unidade de cada voz.

De qualquer forma, funcionam na tradautoria, os dois esquecimentos descritos por Pêcheux (1975/1995), já que o primeiro é a base do segundo, e o segundo é o que torna possível lidar com o primeiro. O esquecimento número 1 , da própria condição de ser sujeito e de significar, ou seja, o esquecimento da inscrição do sujeito na formação discursiva, como sujeito da falha e da contradição, sob a interpelação pelo Outro; e o esquecimento número 2, que o coloca na ilusão da responsabilidade e do controle sobre si mesmo, sobre os sentidos, sobre a dispersão e sobre o outro.

À interpelação e à injunção a interpretar em certa direção, o sujeito responde com a ilusão de responsabilidade e de origem (efeito de autor). O que é da ordem do esquecimento essencial (o da interpelação e injunção) é esquivado/disfarçado pelo que é da ordem do esquecimento enunciativo através do trabalho da tradautoria. $\mathrm{Ou}$ seja, a dispersão é disfarçada pelo efeito de unidade, os deslizamentos pelo de estabilidade, a falha pelo de plenitude, a contradição pelo de coerência. Isso se dá ao re-dizer, re-significar, atualizar.

Organon, Porto Alegre, nº 53, julho-dezembro, 2012, p. 65-78 
Assim, podemos fazer uma passagem da função-autor, como princípio de organização e de efeito de um, efeito de origem (cfe. Foucault, 1969) para a função-tradutor, que lida com o estar entre duas línguas, como princípio que leva ao efeito de proximidade entre dois discursos, ou mesmo de amalgamento. A função-tradutor seria, portanto, uma função do sujeito (interpelação, tomada de posição) no processo da tradautoria, ou seja, da construção da autoria no processo tradutório. É o que se pode observar com o exemplo a seguir. Trata-se do relato do envio de cartas a Macondo pelo "sábio catalão", quando este retorna à Europa:

$\mathrm{Al}$ principio mandaba a decir que todo seguía igual, que en la casa donde nació estaba todavía el caracol rosado, que los arenques secos tenían el mismo sabor en la yesca de pan, que las cascadas de la aldea continuaban perfumándose al atardeecer. Eran outra vez las hojas de cuaderno rezurcidas con garrapatitas moradas, en la cuales dedicaba un párrafo especial a cada uno.

Nepomuceno traduz "garrapatitas moradas" por "carrapatinhos roxos", metáfora que não causa estranheza na leitura da narrativa.

No começo mandava dizer que tudo estava igual, que na casa onde nasceu ainda existia o caracol rosado, que os arenques secos tinham o mesmo sabor na casca de pão, que as cascatas da aldeia continuavam se perfumando no entardecer. De novo eram as folhas de caderno bordadas com carrapatinhos roxos, nas quais dedicava um parágrafo a cada um.

Mas Zagury apresenta em N.T. uma longa explicação sobre a construção da metáfora:

No princípio, mandava dizer que tudo continuava igual, que na casa onde nascera ainda havia o caracol rosado, que os arenques secos tinham o mesmo sabor sobre a torrada, que as cascatas da aldeia continuavam se perfumando ao entardecer. Eram outra vez as folhas de cadernos retomadas com garranchinhos roxos ${ }^{*}$, nas quais dedicava um parágrafo especial para cada um.

* Ao empregar garrapatitas moradas, Gabriel García Márquez faz um jogo verbal: garrapatas é carrapato, enquanto que garrapato é garrancho. É interessante notar que para este mesmo significado existe a palavra

Organon, Porto Alegre, no ${ }^{-53}$, julho-dezembro, 2012, p. 65-78 
escarabajo, que quer dizer também escaravelho. Páginas atrás, o autor se referia ao alfabeto sânscrito como "aranhinhas" e "carrapatos". A importância contrapontística existencial dos insetos no romance é facilmente verificável. Basta lembrar as borboletas amarelas de Mauricio Babilonia, os escorpiões que rondavam o banho de Meme e de Rebeca, a entomologia de Gastón, as formigas ruivas decisivas neste capítulo final, as sanguessugas que quase matam Úrsula (v. a sua relação com os carrapatos), a mordida de escorpião que deixa Arnaldo de Vilanova impotente etc... Por outro lado, a importância existencial dos manuscritos no romance é decisiva - fundamentalmente os pergaminhos de Melquiades - e os escritos do sábio catalão, assim como a sua própria figura, funcionalmente não passam de variações dos primeiros. De modo que as garrapatitas moradas de Gabriel García Márquez assumem um significado ético na cosmovisão do romance, que ultrapassa de longe a mera metáfora sensorial da semelhança de forma expressa pelo equívoco verbal. É a não gratuidade de estilo da expressão, intraduzível, que nos obriga a esta nota. (N. T.)

Se na produção do texto de base, a heterogeneidade é disfarçada pela autoria em efeito de unidade e de origem, na leitura pelo tradutor (assim como por qualquer leitor), desfaz-se o efeito de unidade, e a heterogeneidade possibilita a interpretação, refazendo-se, em seguida, o efeito de unidade. É o que Indursky (2001) chama de heterogeneidade provisoriamente estruturada. Na produção do texto da tradução, a interpretação da construção metafórica por Nepomuceno e por Zagury implica a dispersão, enquanto que a função tradutor reconstrói provisoriamente novamente o efeito de homogeneidade, que ficará em espera por um novo desfiamento pelo leitor do texto da tradução. Mas a N.T. de Zagury denuncia, pondo em destaque, esse processo. E ao fazer isso, toma posição como autora de uma explicação ao leitor, ou seja, a partir do desfazer da unidade, da interpretação em possíveis direções, do conflito entre-línguas (tudo o que faz parte da tradautoria), a tradutora se coloca no lugar de analista da obra, observando a relação entre a palavra em suspenso e narrativa que pode servir de sustentação ao sentido.

Como diz Souza (2010, p.216), o tradutor se encontra numa turbulência:

Tomada no âmbito da história e do discurso, a passagem de um ato de enunciação para outra língua não acontece sem interpelação. Isso

Organon, Porto Alegre, no 53 , julho-dezembro, 2012, p. 65-78 
implica dizer que o sujeito que traduz não pode se constituir a não ser perdendo-se na turbulência dos discursos que se encarregam do destino do dizer submetido à passagem.

É de se pensar não numa interação, nem numa passagem, mas num jogo de tensões, embates, disputas, turbulências acionado na leitura do texto base pelo tradutor, na escrita do texto da tradução, nas leituras possíveis em diferentes épocas e por diferentes lugares sociais, tanto do texto base como do texto da tradução.

Trago aqui mais um trecho para seguir com a reflexão. É sobre Amaranta, já na velhice, perdida no labirinto de suas lembranças, chorando cada vez que ouve as valsas de Pietro Crespi, marco de sua adolescência:

A veces le dolía haber dejado a su paso aquel reguero de miseria, e a veces le daba tanta rabia que se pinchaba los dedos con las agujas, pero más le dolía y más rabia le daba, y más la amargaba el fragante y agusanado guayabal de amor, que iba arrastrando hacia a la morte.

Vejamos inicialmente a tradução de Nepomuceno:

Às vezes doía nela ter deixado aquele rastro de miséria, e às vezes sentia tanta raiva que picava os dedos com a agulha, e mais doía e mais raiva dava, e mais amargava o pomar de amor, ao mesmo tempo fragrante e bichado, que ia arrastando rumo à morte.

O tradutor traduz "guayabal" por "pomar". E os adjetivos que antecedem o substantivo no texto de base são pospostos, na tradução, a "amor", com o acréscimo de "ao mesmo tempo". Além disso, o pronome "la", que no texto de base coloca Amaranta na posição de objeto do sentimento ("y más la amargaba"), não é apresentado no texto da tradução ("e mais amargava”).

Zagury mantém a estrutura sintática do texto de base e traduz "guayabal" por "goiabal" e acrescenta uma N.T.:

Às vezes lhe doía ter deixado com a sua passagem aquele riacho de miséria e às vezes sentia tanta raiva que espetava os dedos nas agulhas, porém mais lhe doía e com mais raiva ficava e mais lhe amargava o fragrante e bichado goiabal de amor que ia arrastando até a morte.*

Organon, Porto Alegre, nํ53, julho-dezembro, 2012, p. 65-78 
* Tendo sido impossível encontrar uma expressão equivalente em português ao excelente "achado" literário de Gabriel García Márquez, feito sobre um emprego regional (Antilhas, Colômbia e El Salvador) do guayaba, preferimos manter a imagem, acrescida desta nota: a goiaba é uma fruta que bicha com muita freqüência e sem apresentar marcas externas que sirvam de aviso à pessoa que come. A partir dai, da conotação afetiva de frustração que se desenvolveu no seu significado, a palavra passou a ser empregada em sentido figurado, nas regiões da América Hispânica que assinalamos, com a denotação de mentira, embuste. Gabriel García Márquez vai aproveitar a expressividade do uso lingüístico popular recriando-o analiticamente, através, principalmente, da adjetivação contrastante fragante $\mathrm{y}$ agusanado - não só o desequilíbrio entre a caracterização eticamente positiva fragante e a eticamente negativa agusanado entra na conta da expressividade; também a própria escolha das palavras na série sinonímica vem a intensificar o desequilíbrio, já que fragrante é um termo que pertence à tradição do clichê literário ("nobre", portanto), enquanto que agusanado é o termo normal da linguagem agrícola sem idealização estética. A hipérbole guayabal intensifica grotescamente a ironia da adjetivação. (N. T.)

A tradutora trabalha o sentido a partir de duas formações discursivas, para significar "fragante y agusanado guayabal de amor". É dessa tensão entre saberes de diferentes formações discursivas - que faz funcionar a metáfora - que se dá a produção dos efeitos de sentidos.

Diante da palavra, o tradutor se encontra ora frente à falta, ora frente ao excesso, seleciona uma palavra e descarta outras. Diante da fissura, do escape, recorre à N.T., o que faz com que ela funcione como uma forma de contenção, mas é uma costura que deixa a marca do rasgo. E o rasgo é a própria possibilidade de interpretar. Nessa direção, cito novamente de Souza (2010, p.215):

Como seria pensar o sujeito, efeito de equívoco, enunciando não mais fixado apenas em certo sistema linguístico, mas no seu dizer em trânsito entre uma língua e outra? O que se passa quando o caso não é falar uma mesma língua de muitos modos, mas simplesmente falar em mais de uma, sendo incitado a transferir relações de sentido e interpelado no ponto em que simbolicamente um espaço linguístico é irredutível a outro, e que portanto são mutuamente irredutíveis os sentidos que se processam em distintos territórios linguísticos?

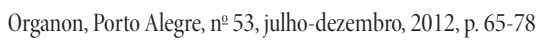


Para pensar essa turbulência, esse equívoco e esses territórios linguísticos, recorro a Pêcheux, com o efeito metafórico, ou seja, o deslizamento do enunciado como a própria possibilidade de interpretar, já que se trata sempre de uma palavra por outra, entre pontos de deriva, diante de uma demanda de interpretação. Diz-nos Pêcheux (2011[1984], p.158) sobre a metáfora: "não há, de início, uma estrutura sêmica do objeto, e em seguida aplicações variadas dessa estrutura nesta ou naquela situação, mas que a referência discursiva do objeto já é construída em formações discursivas (técnicas, morais, políticas...)".

É isso que possibilita a tradução, levando, por um lado, à seleção e, por outro, à renúncia. Ou seja, o sentido se dá pela formação discursiva, ou ainda no espaço/tensão/choque entre formações discursivas, "das quais nenhuma pode ser considerada originária" (Idem). E isso é fundamental para contestar o imaginário tradicional de tradução como transporte.

Nas bordas porosas do discurso marcam presença-ausência: outros discursos possíveis na mesma formação discursiva (o que pode/deve ser dito), bem como outros discursos impossíveis naquela formação discursiva (o que não pode / não deve ser dito), mas presentes no interdiscurso. Então o trabalho do tradutor se dá sobre essas presenças-ausências, sobre os rasgos, sobre os deslizamentos, entre o imposto e o interditado.

Retorno a Pêcheux em sua maneira de relacionar metáfora, formação discursiva e interdiscurso:

Nessa perspectiva, o interdiscurso, longe de ser efeito integrador da discursividade torna-se desde então seu princípio de funcionamento: é porque os elementos da sequência textual, funcionando em uma formação discursiva dada, podem ser importados (meta-forizados) de uma sequência pertencente a uma outra formação discursiva que as referências discursivas podem se construir e se deslocar historicamente. (Idem)

Como já disse em outro texto (2010), a natureza do discurso é da ordem do repetível, do já-lá do interdiscurso que funciona sob a forma de fluxo e refluxo, pela memória (sob a determinação de uma formação discursiva na qual o sujeito se inscreve para fazer sentido), no intradiscurso. E é assim, portanto, que ocorre a tradautoria.

Organon, Porto Alegre, n⿳ำ 53, julho-dezembro, 2012, p. 65-78 
Por isso, considero que o trabalho do tradutor é o de percorrer os espaços de silêncio para aquém, para além e por entre as palavras, levantar hipóteses sobre possíveis não-ditos e já-ditos em outro lugar, desconfiar da transparência, da unicidade, da língua regulada e, principalmente, tomar posição.

O enfrentamento do tradutor com opacidade do texto e da língua, com a metáfora pontual e com o efeito metafórico constitutivo de todo dizer/interpretar, com os equívocos, deslizamentos e urgências de contenção, sua atuação sob o esquecimento número 2 , no processo da tradautoria, tudo isso pode levar a discussões produtivas no âmbito dos estudos da tradução, bem como no da Análise do Discurso. Esse é um diálogo que se apresenta cada vez mais premente.

\section{REFERÊNCIAS}

GARCÍA MÁRQUEZ. Cien años de soledad. Buenos Aires: Editorial Sudamericana, 1974.

. Cem anos de solidão. Tradução de Eliane Zagury. 39.ed. Rio de Janeiro: Record, 1994.

. Cem anos de solidão. Tradução de Eric Nepomuceno. 77.ed. Rio

de Janeiro: Record, 2011.

GARCÍA MÁRQUEZ, Gabriel; MENDOZA, Plinio Apuleyo. El olor de la Guayaba. Barcelona: Mondadori, 1994.

FOUCAULT, Michel. O que é um autor? In: . O que é um autor?

3.ed. [S.l.], Portugal: Vega, 1992. p.29-87.

INDURSKY, Freda. Da heterogeneidade do discurso à heterogeneidade do texto e suas implicações no processo da leitura. In: ERNST-PEREIRA, A.; FUNCK, S. B. A leitura e a escrita como práticas discursivas. Pelotas: Educat, 2001.

LYRA, Regina Maria de O. T. de. Explicar é preciso? Notas de tradutor: quando, como e onde. Fragmentos, Florianópolis, v.8, n.1, p. 73-87, juldez/1998.

MITTMANN, Solange. Notas do tradutor e processo tradutório: análise e reflexão sob uma perspectiva discursiva. Porto Alegre: Editora da UFRGS, 2003.

- Autoria e tradução: da dispersão às identificações. In:

Organon, Porto Alegre, ํำ 53, julho-dezembro, 2012, p. 65-78 
MITTMANN, S.; GRIGLETTO, E.; CAZARIN, E.A.. (Org.). Práticas discursivas e identitárias: sujeito e língua. Porto Alegre: Nova Prova, 2008 , v. , p. $80-96$.

. Heterogeneidade constitutiva, contradição histórica e sintaxe. Desenredo, Passo Fundo, v.6,n.1, p.85-101, jan./jun.2010.

PÊCHEUX, Michel. Metáfora e interdiscurso. Trad. Eni P. Orlandi. In: __ Análise do Discurso. Textos selecionados: Eni P. Orlandi. Campinas: Pontes, 2011[1984]. p.151-161.

. Semântica e discurso: uma crítica à afirmação do óbvio. Tradução de Eni P.Orlandi [et al.] 2.ed. Campinas: Unicamp, 1995 [1975].

SERRANI-INFANTE, Silvana. Identidade e segundas línguas: as identificações no discurso. In: SIGNORINI, Inês. Lingua(gem) $e$ identidade: elementos para uma discussão no campo aplicado. Campinas: Mercado de Letras; São Paulo: Fapesp, 1998. p.231-264.

SOUZA, Pedro de. De como se perder na tradução. Cadernos de tradução, Florianópolis, p. 213-224, 2010.

TFOUNI, Leda Verdiani. Autoria e contenção da deriva. In: (Org.) Múltiplas faces da autoria. Ijuí: Editora Unijuí, 2008. p.141-158.

Recebido em: 19/11/2012. Aprovado em: 20/11/2012. 